\title{
Evaluation of theory of mind: A study with students from public and private schools
}

\author{
Avaliação da teoria da mente: estudo com alunos \\ de escolas públicas e particulares mineiras
}

\author{
Marisa Cosenza RODRIGUES ${ }^{1}$ \\ Maíze Carla Costa PELISSON² \\ Flávia Fraga SILVEIRA² \\ Nathalie Nehmy RIBEIRO3 \\ Renata de Lourdes Miguel da SILVA ${ }^{3}$
}

\begin{abstract}
This study assessed the development of the theory of mind in preschool children aged 4 and 5 years old, along with potential interactions among gender, age and whether children were from private or public schools. A total of 178 children (91 students from public schools and 87 from private schools) participated in the study. After securing ethical compliance with applicable guidelines, we applied the Theory-of-Mind-Scale. There was no evidence of differences regarding gender $(p<0.38)$. Differences were found in regard to age $(p<0.001)$ and whether students were from private or public schools $(p<0.008)$. Five-year-old children performed better on the scale and children from private schools also performed better than those from public schools. The results show that the scale was sufficiently sensitive to capture the evolutionary sequence of the theory of mind and the relevance of socio-cultural factors. Because research in this field is still incipient, we emphasize the importance of further studies conducted with larger samples.
\end{abstract}

Keywords: Cognitive development; Philosophy of mind; Preschool students.

\section{Resumo}

Este estudo avalia o desenvolvimento da teoria da mente em pré-escolares de 4 e 5 anos de idade, bem como as possíveis interações entre as variáveis gênero, idade e rede de ensino. Participaram da pesquisa 178 crianças, das quais 91 alunos de escolas públicas e 87 de escolas particulares. Após procedimentos éticos, aplicou-se a Escala de Teoria da Mente. Não foi evidenciada distinção quanto ao gênero $(p<0,38)$. Foram verificadas diferenças quanto à idade $(p<0,001)$ e rede de ensino $(p<0,008)$. Crianças de 5 anos obtiveram melhor desempenho na escala. As crianças oriundas de escolas particulares apresentaram um desempenho superior às das escolas públicas. Resultados indicam que a escala foi sensível para captar a sequência evolutiva da teoria da mente e a relevância dos fatores socioculturais. Por ser uma área ainda em fase emergente de investigação no Brasil, ressalta-se a importância de estudos com amostras maiores.

Palavras-chave: Desenvolvimento cognitivo; Filosofia da mente; Pré-escolares.

\section{$\boldsymbol{v} \mathbf{v} \boldsymbol{v}$}

${ }^{1}$ Universidade Federal de Juiz de Fora, Instituto de Ciências Humanas, Departamento de Psicologia. R. José Lourenço Kelmer, s/n., Campus Universitário, São Pedro, 36036-330, Juiz de Fora, MG, Brasil. Correspondência para/Correspondence to: M.C. RODRIGUES. E-mail: <rodriguesma@terra.com.br>.

2 Universidade Federal de Juiz de Fora, Instituto de Ciências Humanas, Curso de Psicologia. Juiz de Fora, MG, Brasil.

3 Psicóloga. Juiz de Fora, MG, Brasil.

Support: Fundação de Amparo à Pesquisa do Estado de Minas Gerais (Processo: APQ-01049-11). 
Increased interest has been observed in the last three decades in regard to the study of the theory of mind. This field, extremely important for child socio-cognitive development, investigates children's ability to represent their own and others' mental states through the attribution of beliefs, emotions and intentions in order to predict their actions more accurately. Shakoor et al. (2012) highlight that abilities involved in this development are essential to a child's socialization and interaction, as well as for school adaptation in the first years of life. When children acquire these skills they become more adept at decoding social cues and in modeling behavior in order to interact with their social environment more satisfactorily.

In regard to the process of acquiring mental states, Carpendale and Lewis (2006) stress that children at the age of two understand that desires move human actions and that mental states are not observable or tangible. Lane, Wellman, Olson, LaBounty, and Kerr (2010) state that at the age of three, children are able to identify basic emotional expressions and understand that individuals experiencing similar situations may have different desires and express emotions differently in comparison to their own desires and emotional expressions. At four years old, as sustained by Carpendale and Lewis, (2006) children develop the ability to differentiate between beliefs and desires and also wield a more developed understanding concerning mental states. Lane et al. (2010) state that five-year old children show an understanding that individuals may have an internal emotion different from what they express in a given situation.

The interest in investigating the understanding of mental states emerged in the field of animal cognition in the 1970s. The term theory of mind was first used by Premack and Woodruff (1978). They studied this ability in chimpanzees and, based on this study, at the beginning of the 1980s, some researchers (J. H. Flavell, Flavell, \& Green, 1983; Perner, Leekam, \& Wimmer, 1987; Wimmer \& Perner, 1983) interested in studying child understanding concerning mental states developed false-belief tasks to assess children's abilities to

$\mathbf{2 1 4}$ recognize that another person may have a belief that differs from their own beliefs and reality. This methodological resource became a benchmark for research in the field. Aiming to investigate the methodology used in studies conducted in the last three decades of the $20^{\text {th }}$ century, Benavides and Roncancio (2009) conducted a review that confirms the frequent use of false-belief tasks to investigate the development of children's ability to understand mental states. The authors observed a predominance of cross-sectional studies with an emphasis on age and performance.

Wellman and Liu (2004), defending the idea that the ability to attribute mental states is not restricted to the study of false belief but includes the understanding of a set of abilities such as the understanding of emotions and desires, developed a scale to enable the assessment of the theory of mind more broadly. In this publication, the authors first report a meta-analysis intended to gather tasks concerning the theory of mind and categorize them. Based on the results, Wellman and Liu grouped the tasks into increasing level of complexity, namely: 1) different desires; 2 ) different beliefs; 3 ) access to knowledge; 4) false belief; 5) explicit false belief; 6) belief and emotion; 7) real and apparent emotion. The Theory-of-Mind Scale with seven tasks assessing different aspects concerning the understanding of mental states was tested on a sample of 75 American children aged from 2 to 6 years old.

This scale has been used in some international studies. The study by Wellman, Fang, Liu, Zhu, and Liu (2006) aimed to verify whether cultural experiences influence the development of the theory of mind. Understanding concerning mental states in a sample of 140 Chinese children (3 to 5 years old) was investigated and compared with that of English-speaking children (American and Australian) in the same age range. In general, the results were similar, indicating that older children performed better. Chinese children, however, presented cognitive understanding of mental states in the access to knowledge task, while Englishspeaking children show such an understanding in false-belief tasks. The authors explain that sociocultural factors may account for these differences. A consistent sequence was verified in 
the performance of tasks in both groups in regard to an understanding of the theory of mind.

Shahaeian, Peterson, Slaughter, and Wellman (2011) conducted a cross-cultural study to examine the cultural contrasts that may influence the development of a child's theory of mind. They compared the performance of 135 children aged between 3 and 6 years old (77 Australian and 58 Iranian children). They applied five tasks from Wellman and Liu's scale (different desires; different beliefs; access to knowledge; false belief; and realapparent emotion). An intercultural difference was found in the sequencing of the steps of the theory of mind but not in regard to the scale's total score. The understanding of access to knowledge among Iranians preceded understanding that people may have different beliefs. This finding diverged form what was presented by the sample of Australian children. The authors inferred that differences in regard to cultural aspects may have played a positive role in the acquisition of the theory of mind among Iranian children, with an emphasis on collectivism that is characteristic of Eastern cultures, in which greater attention is given to attributes such as filial respect, avoidance of disputes, and the acquisition of knowledge.

In Brazil, an important step toward the use of the Theory-of-Mind Scale was taken with a study conducted by Domingues, Valério, Panciera, and Maluf (2007). They translated Wellman and Liu's scale for use in Brazil. This study enabled investigating aspects that go beyond the investigation of false belief (Maluf, Gallo-Penna, \& Santos, 2011; Miguel-Silva, 2012; Noé, 2011; Ribas, 2011).

Ribas (2011) compared the performance of 115 children aged from 6 to 7 years old from public schools in regard to the development of the theory of mind using Wellman and Liu's scale and in regard to emotional understanding applying the Emotional Intelligence Test for Children (Bueno, 2008). The author also compared the children in terms of sex and assessed the manifestation of aggressive behavior using the Teacher's Perception Scale of School Children Aggressive Behavior (Lisboa \& Koller, 2001). The results enabled establishing two groups: 30 children considered to be aggressive and 30 non-aggressive children. The results indicated a relationship between theory of mind and social development, suggesting that the ability to understand emotions influences children's socioemotional development. No differences were found in regard to sex, though non-aggressive children presented superior performance in regard to the studied variables. In regard to performance on the scale's tasks, higher scores were found for the third task (access to knowledge) in comparison to task two (different beliefs). The author notes the multifactorial nature of the theory of mind, questioning the applicability of the scale among Brazilian children, since a decreasing performance was expected among the children in the tasks because the scale is organized with increasing levels of complexity.

Using this same scale, Maluf et al. (2011) investigated the relationship between theory of mind and conversational understanding. Tasks of conversational understanding and four tasks presented by the scale (different beliefs; access to knowledge; false belief; explicit false belief) were applied to 28 children ( 4 and 5 years old) with low socioeconomic levels. An effect of age on the acquisition of skills to understand conversational rules, as well as to understand mental states, was identified among 5-year-old children. The hypothesis that there is an association between these two abilities was also supported. Both groups performed better on task five, which concerned explicit false belief, than on task four (false belief). Lower rates of correct answers were observed among younger children in regard to their performance on the scale, such as in the case of task two, addressing different beliefs, and task 4, addressing false beliefs. The fiveyear-old children performed better on the first two tasks, with a reduced rate of correct answers for subsequent tasks. Given these results, the authors suggest a differentiated assessment of these tasks among Brazilian children as, once again, performance was not consistent with the degree of complexity of tasks as shown in international studies.

More recently, Miguel-Silva (2012) investigated the correlation among theory of mind, language 
concerning mental states, and social competence in 85 children ( 6 and 7 years old) from two public schools (one located in a central area and another located in a peripheral area of a city in Minas Gerais, Brazil). Potential differences regarding gender and schools were also verified. A book of narratives using images was employed to assess the attribution of mental states together with the Theory of Mind Scale (Wellman \& Liu, 2004) and Social Skills Rating System - Brazilian version (SSRS - BR) (Bandeira, Z.A.P. Del Prette, Del Prette, \& Magalhães, 2009) to investigate social competence (children's selfassessment and teachers' assessment). Differences in regard to gender and schools were observed for the language and social competence variables, but no differences were found in these factors in regard to the theory of mind. The comparison of the performances of children per tasks in the theoryof-mind scale showed that children performed better on task 6, which addresses belief and emotion, than on task four (false belief); performance was also better for task 3, which concerns access to knowledge, than for task 2, which addresses different beliefs. Superior performance was also observed on tasks 6 and 7 (real-apparent emotion) than on task 5, concerning explicit false belief. Additionally, correlation was found among the studied variables. According to the author, data concerning the Theory-of-Mind Scale reinforce the view that the order of performance by tasks is different from the pattern presented by the American children who participated in the first study conducted by Wellman and Liu (2004).

Authors such as Wellman, Fang, and Peterson (2011) stress the importance of taking into account the sociocultural, family and school experiences of children in the development of understanding regarding mental states. This avenue includes studies addressing interventions that show positive effects on child socio-cognitive improvement. Among these are Brazilian studies investigating potential relationships between the development of the theory of mind and some aspects related to education, such as reading comprehension (Noé, 216 2011).
One study conducted by Noé (2011) addressed 77 students, aged 7 years old on average, from a public school and designed to assess and compare their performances on the tasks presented by the Theory-of-Mind Scale proposed by Wellman and Liu with reading comprehension. Additionally, the author sought to verify the efficiency of an intervention conducted by Rodrigues, Ribeiro and Cunha (2012). This intervention was designed to promote children's mental language through dialogically exploring children's storybooks. The performance of a group of children participating in the intervention was compared to that of nonparticipant children. Reading comprehension was measured through a Cloze procedure (Santos, 2004), adapted to identify and compare categories of mental terms attributed to the text. It was expected that as the participant children improved their mental language, they would broaden their understanding of mental states, performing better on the theory-of-mind tasks and reading tests. Nonetheless, similar results were observed between the two groups. The author suggests that individual factors not addressed by the study such as socioeconomic status, parenting styles, fraternal relationships, and experiences with storybooks at school, among other factors, may have contributed to the similarities found between the groups.

Another relevant factor reported by Noé (2011) was the high performance of children from both groups on the scale, which is in agreement with the literature predicting satisfactory performance for this age range. In regard to the performance of children by task, participant children presented a higher performance on task three, which concerns access to knowledge, than on task two, which addresses different beliefs; better performance was also observed on task 6, regarding belief and emotion, than on task five concerning understanding of an explicit false belief. The nonparticipant children, in turn, performed better on task five than on task 4 (false belief). Both groups performed better on task 6 (belief and emotion) than on task four (false belief). Noé asserts that the socio-cognitive development program, which focused on the intentional and dialogical exploration 
of terms concerning internal states during reading with children, may account for the improved performance on task 6 , which concerns understanding of belief and emotion.

Considering the importance of developing studies addressing the theory of mind and of broadening results concerning the Theory-of-Mind Scale in the Brazilian context, we sought to investigate in this study the development of this ability among preschool children from both private and public schools in a city in Minas Gerais, Brazil. The variables age, gender, and whether the child attended a public or private school were also taken into account.

\section{Method}

\section{Participants}

A total of 178 children attending preschool, aged from 4 years and five months to 5 years and four months, from Juiz de Fora (MG), Brazil participated in the study. Of these, 91 (44 boys and 47 girls) attended two public schools and 87 (41 boys and 46 girls) attended two private schools. The choice of schools was not probabilistic; the schools were chosen according to their nature, public or private, accessibility and number of children.

\section{Instruments}

The following resources were used for data collection: a) Questionnaire characterizing the children, addressing data such as age (date of birth), gender, and socioeconomic class. These data were collected from documents provided by the schools; b) The Theory-of-Mind Scale by Wellman and Liu (2004), which was translated by Domingues et al. (2007) for the Brazilian context, the maximum score of which is seven points. This scale is composed of seven tasks (1. different desires; 2 . different beliefs; 3. access to knowledge; 4. false belief; 5 . explicit false belief; 6 . belief and emotions; 7 . real and apparent emotion) sequentially organized in increasingly levels of complexity, which enables the capture of the child's level of development in terms of seven aspects linked to the development of the theory of mind and mental states.

The following material was used in the scale's application: one action figure and one big doll; three action figures and one small doll; sheets containing separate images of one carrot, one cookie, one garage, one tree, one backpack, one cupboard, one puppy and one piglet; one small box; one BandAid box; one box of chocolates; small stones; a sheet with the drawing of three faces (a happy face, a neutral face, and a sad face), and another sheet containing the image of a boy on his back. Note that these elements were the same used in the studies conducted by Noé (2011), Ribas (2011) and Miguel-Silva (2012) so that a standard application of the instrument was maintained, taking into consideration that the variation of characteristics such as dolls' size, color, and format could influence the data collection.

\section{Procedures}

After the schools and the Institutional Review Board at the Universidade Federal de Juiz de Fora (UFJF) authorized the study, a meeting was scheduled in the schools with the parents to explain the study's objectives and to ask them to sign Free and Informed Consent Forms. After this procedure and with the list of 4 to 5 year-old children, we collected information concerning the groups of participant children. Afterwards, a meeting was scheduled with each of the four schools with the teachers of the respective children to clarify the study's objectives and importance and also to schedule appropriate days and times to collect the children's data. Then, we verified the universe of children in each school to analyze their records and complete the instrument concerning the children's characterization. Good rapport was established with the children who received clarification in regard to the data collection procedures using examples of the classroom routine. Children also provided their verbal consent and data were collected individually in a private room within the school's premises. 
In the application of the Theory-of-Mind Scale, short stories were told to the children in each task using the aforementioned instruments. At the end of each story, questions were asked to assess the understanding of different abilities related to theory of mind. Each task was assessed assigning zero to each incorrect answer and one point to each correct answer.

Data concerning the Theory-of-Mind were tabulated and analyzed quantitatively. Performance on the scale was examined using mean and standard deviation and the results were described using percentages of predictor variables (age, public or private school, and gender). Analysis of Variance was used to simultaneously verify differences and interactions among the means of scores obtained on the Theory-of-Mind Scale among three variables (age, public or private school, and gender). Analysis of variance simultaneously verified the differences and interactions among the means of scores obtained on the Theory-of-Mind Scale among the three variables (age, public or private school, gender). Finally, the Multiple Linear Regression Model was used to verify whether there potential differences among the predictor variables were significant.

This study was approved by the Institutional Review Board at the UFJF on May 19 ${ }^{\text {th }}, 2011$ (Referee report n0 092/2011 - Protocol CEP-UFJF: 2342.82.2011).

\section{Results and Discussion}

The results obtained by the participants distributed by age indicate that the group of 5 yearold children obtained higher means (Mean - $M=$ 4.61; Standard Deviation $-S D=1.38$ ) in comparison to 4 year-old children $(M=3.41, S D=1.57)$ and this difference was significant $(p<0.001)$. These results converge with those obtained by Maluf et al. (2011), where older children also performed better on the Theory-of-Mind Scale proposed by Wellman and Liu (2004). In regard to age, this study's results are in accordance with those reported by Carpendale and Lewis (2006), Lane et al. (2010) and Shakoor et al. (2012). These authors believe in a gradual progression of understanding of mental states in the process of acquiring the theory of mind.

An analysis concerning the performance by task considering the participants' age was also performed.

As shown in Figure 1, the children's performance does not follow a descending pattern, which differs from the results found by Wellman and Liu (2004) with American children. Four-year old children performed better on the explicit false belief task and also on the belief and emotion task in comparison to the false belief task. Still in regard to this group, its performance on the real-apparent emotion task exceeded their performance for the false belief task. Better performance was observed among five-year old children in regard to the access to knowledge task when compared to different beliefs task. They also performed better in the belief and emotion and real-apparent emotion tasks than they did in the false belief task.

Brazilian studies (Maluf et al., 2011; Miguel-Silva, 2012; Noé, 2011; Ribas, 2011) found results similar to those presented by this study's participants. The convergence of results in studies addressing Brazilian children may indicate the interference of factors related to the cultural context
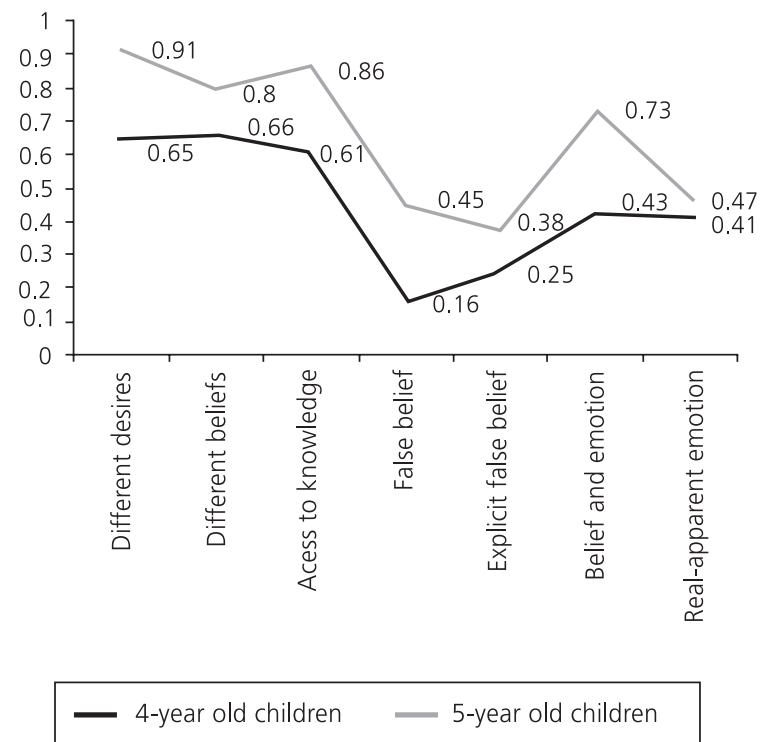

Figure 1. Curves of performance of participants by age. 
in the acquisition of the theory of mind, as described by Shahaeian et al. (2011). It is important to note that studies conducted in other sociocultural contexts also found differences in regard to the developmental sequence of the theory of mind, such as when Chinese children are compared to American and Australian children (Wellman et al. 2006) or when Iranian children are compared with Australian children (Shahaeian et al., 2011).

The second analysis took into account whether the participants attended public or private schools. Students from private schools $(M=4.39$; $S D=1.58)$ obtained more expressive results than did those from public schools $(M=3.79 ; S D=1.53)$, with significant differences $(p<0.008)$. In this sense, our findings are consistent with the considerations put forward by Wellman et al. (2011), i.e., they note the relevance of children's sociocultural, family and school experiences.

No studies were found reporting results concerning the application of the Theory-of-Mind Scale among Brazilian children attending private and public schools. This is a potential line of research for future studies. Such a difference may account for potential differences between experiences of children in different school contexts, which is in agreement with studies following this direction of research (Shahaeian et al., 2011; Wellman et al., 2011). These findings open up new possibilities for investigations that may broaden the relationship of these factors with the acquisition of the theory of mind.

Based on the differences found between age and whether children attended public or private schools, we used the Multiple Linear Regression Model to verify whether these differences found in the children's performance were significant, as shown in Table 1.

We verified that the difference between ages was more pronounced than the differences found between students from private and public schools. The Beta coefficient concerning the age variable is higher than that found for different kinds of school. There is a direct relationship for the age factor, which positively affects performance on the Theory-ofMind Scale, while attending a public school negatively impacts performance.

Finally, the analysis was performed considering the sex variable, which showed that girls performed better ( $M=4.22 ; S D=1.54$ ) in comparison to boys $(M=3.94 ; S D=1.62)$. This difference, however, was not significant $(p<0.38)$, which agrees with Brazilian studies conducted by Ribas (2011) and Miguel-Silva (2012), who also reported no differences in regard to gender.

Socio-cognitive development greatly influences the lives of children. As discussed earlier, the understanding of mental states is linked to aspects that are important for daily interactions, and more broadly, to the understanding of the social world.

The literature assumes as the main hypothesis that there is a gradual evolution of mental states in the process of acquiring the theory of mind. This study corroborates this hypothesis, based on the result that five-year old children performed better than four-your old children. Therefore, the scale used was sensitive enough to capture the evolutionary sequence of the theory of mind in the children under study.

The theory of mind is an emergent field of investigation in Brazil and few studies use the Theory-of-Mind Scale. There is, therefore, a need

Table 1

Multiple Linear Regression Model

\begin{tabular}{|c|c|c|c|c|c|}
\hline \multirow{2}{*}{ Variables } & \multicolumn{2}{|c|}{ Non-standardized coefficients } & \multirow{2}{*}{$\begin{array}{c}\text { Standardized coefficients } \\
\text { Beta }\end{array}$} & \multirow{2}{*}{$\begin{array}{l}t \\
\mathrm{~B}\end{array}$} & \multirow{2}{*}{$\begin{array}{r}\text { Sig. } \\
S D\end{array}$} \\
\hline & B & $S D$ & & & \\
\hline Constant & 4.017 & 0.109 & & 36.755 & 0.000 \\
\hline Public or Private & -0.285 & 0.108 & -0.180 & -2.625 & 0.009 \\
\hline Age & 0.593 & 0.109 & 0.372 & 5.421 & 0.000 \\
\hline
\end{tabular}

Note: B: Not standardized coefficient of multiple linear regression modal; SD: Standard Deviation; Sig.: Significance. 
for further studies addressing larger and more diversified samples to verify the evolutionary sequence that is most representative of the real acquisition of content of the scale's tasks among Brazilian children. In this sense, the validation of the scale in the Brazilian context becomes imperative. It is expected that the results found in this study will contribute to this field of investigation.

\section{References}

Bandeira, M., Del Prette, Z. A. P., Del Prette, A., \& Magalhães, T. (2009). Validação das Escalas de Habilidades Sociais, Comportamentos Problemáticos e Competência Acadêmica (SSRS - BR) no ensino fundamental. Psicologia: Teoria e Pesquisa, 25(2), 271-282.

Benavides, J. D., \& Roncancio, M. M. (2009). Conceptos de desarrollo en estudios sobre Teoría de la Mente en las últimas tres décadas. Avances en Psicología Latinoamericana, 27(2), 297-310.

Bueno, J. M. H. (2008). Construção de um instrumento para avaliação da inteligência emocional em crianças (Tese de doutorado não-publicada). Universidade São Francisco, Itatiba.

Carpendale, J., \& Lewis, C. (2006). How children develop social understanding. Malden: Blackwell Publishing.

Domingues, S. F. S., Valério, A., Panciera, S. D. P., \& Maluf, M. R. (2007). Tarefas de crença falsa na avaliação de atribuição de estados mentais. In P. W. Shelini (Org.), Alguns domínios da avaliação psicológica (pp.141-162). Campinas: Alínea.

Flavell, J. H., Flavell, E. R., \& Green, F. L. (1983). Development of the appearance-reality distinction. Cognitive Psychology, 15(2), 95-120.

Lane, J. D., Wellman, H. M., Olson, S. L., LaBounty, J., \& Kerr, D. C. R. (2010). Theory of mind and emotion understanding predict moral development. Early childhood British Journal of Developmental Psychology, 28(4), 871-889.

Lisboa, C. S. M., \& Koller, S. H. (2001). Escala de percepção por professores dos comportamentos agressivos de crianças na escola. Psicologia em Estudo, 6(1), 59-69.

Maluf, M. R., Gallo-Penna, E. C., \& Santos, M. J. (2011). Atribuição de estados mentais e compreensão conversacional: estudo com pré-escolares. Paidéia, 21(48), 41-50.
Miguel-Silva, R. L. (2012). Teoria da mente, linguagem e competência social: um estudo comparativo com alunos do ensino fundamental (Dissertação de mestrado não-publicada). Universidade Federal de Juiz de Fora.

Noé, P. A. A. B. (2011). Teoria da Mente e compreensão leitora: um estudo com alunos participantes de um programa promotor de desenvolvimento sociocognitivo (Dissertação de mestrado não-publicada). Universidade Federal de Juiz de Fora.

Perner, J., Leekam, S. R., \& Wimmer, H. (1987). Threeyear old's difficulty with false belief. British Journal of Developmental Psychology, 5(2), 125-137.

Premack, D., \& Woodruff, G. (1978). Does the chimpanzees have a theory of mind? Behavioral and Brain Science, 1(4), 515-526.

Ribas, D. A. (2011). Teoria da Mente e Compreensão das emoções: um estudo comparativo com alunos do ensino fundamental (Dissertação de mestrado nãopublicada). Universidade Federal de Juiz de Fora.

Rodrigues, M. C., Ribeiro, N. N., \& Cunha, P. C. (2012). Leitura mediada com enfoque sociocognitivo: avaliação de uma pesquisa-intervenção. Paidéia, 22(53), 393-402.

Santos, A. A. A. (2004). O Cloze como técnica de diagnóstico e remediação da compreensão em leitura. Interação em Psicologia, 8(2), 217-226.

Shahaeian, A., Peterson, C. C., Slaughter, V., \& Wellman, H. M. (2011). Culture and the sequence of steps in theory of mind development. Developmental Psychology, 47(5), 1239-1247.

Shakoor, S., Jaffee, S. R., Bowes, L., Ouellet-Morin, I., Andreou, P., Happé, F., ... Arseneault, L. (2012). A prospective longitudinal study of children's theory of mind and adolescent involvement in bullying. Journal of Child Psychology and Psychiatry, 53(3), 254-261.

Wellman, H. M., Fang, F., Liu, D., Zhu, L., \& Liu, G. (2006). Scaling of theory of mind understanding in Chinese children. Psychological Sciences, 17(12), 1075-1081.

Wellman, H. M., Fang, F., \& Peterson, C. C. (2011). Sequential progressions in a Theory-of-Mind Scale: Longitudinal perspectives. Child Development, 82(3), 780-792.

Wellman, H. M., \& Liu, D. (2004). Scaling of Theory-ofMind tasks. Child Development, 75(2), 523-541.

Wimmer, H., \& Perner, J. (1983). Beliefs about beliefs: Representation and constraining function of wrong beliefs in yong children's understanding of deception. Cognition, 13(1), 103-128.

Received: August 22, 2013

Approved: December 18, 2013 